\title{
O ENGENHO MOTOR DA INFORMATIZAÇÃO
}

\section{Murilo Cardoso de Castro}

Raquel Cardoso de Castro

João Cardoso de Castro

\section{Resumo:}

O desenvolvimento desse trabalho se fundamentou integralmente nas idéias de Pierre Lévy. Começamos por uma reflexão sobre a "máquina universal", fundamento da informática e da informatização, se passará em revista sua instituição, buscando em Ludwig Wittgenstein suas raízes filosóficas, até mesmo metafísicas. Por último, uma breve análise do paradigma da informática deve formalizar as principais conclusões desta exposição.

Palavras-Chaves:

Informatização; Máquina universal; Lógica

\section{THE MOTOR MACHINE OF COMPUTERIZATION}

\begin{abstract}
:
The development of this work is entirely based on the ideas of Pierre Lévy. We begin with a reflection on the "Universal machine", the foundation of informatics and computerization, it will also review its establishment, seeking their philosophical roots in Ludwig Wittgenstein, even the metaphysical aspect. Finally, a brief analysis of the informatics paradigm should formalize the main conclusions of this explanation.
\end{abstract}

\section{Keywords:}

Computerization; Universal machine; Logic 


\section{Introdução}

A informática surge no cenário científico-tecnológico, após a segunda grande guerra, como a manifestação última da meta-arquitetura da Razão Moderna, em elaboração desde a Renascença, de forma subjacente e singular ao Ocidente - a "máquina universal”. A informática revela um dos segredos da história do pensamento ocidental, a forma oculta de seu ideal democrático, o motor invisível de sua arte, o selo de sua potência industrial e científica - talvez a própria essência do que se chama Ocidente.

A “máquina universal”, como conceito elaborado no campo da lógica matemática, se apresenta como um engenho capaz de "tratar a informação": transformar, segundo uma lei determinada, uma mensagem (entendida como um conjunto de dados) de entrada em uma mensagem de saída. O computador, seu suporte material, nada mais é do que a ponta atualmente visível deste imenso iceberg, a insinuante manifestação técnica desta configuração subterrânea (LÉVY, 1987).

A diferença entre um tratamento industrial e um tratamento informacional reside primeiramente no campo onde atuam: material e intelectual, e também na quantidade de energia aplicada no processo de transformação em um e em outro campo. Rigorosamente os dois tratamentos são de informação, entretanto, no tratamento informacional, a energia aplicada é mínima, e destina-se à conhecer, supervisionar, controlar, comandar, direta ou indiretamente, processos de um nível de energia superior.

O fato de atuar no campo intelectual faz com que o aprendizado de uma "tecnologia da inteligência”, como a informática por exemplo, seja uma empreitada "sem fim”, onde o que se transmite em qualquer processo educacional é apenas a maneira de "manipular” a tecnologia, ficando geralmente de fora a metodologia que rege sua aplicação, assim como o potencial de desenvolvimento na sua adoção, que geralmente só se vai aprender por um longo e árduo processo pessoal de “experimentação” em uso (o que explica as dificuldades de conclusão satisfatória de qualquer projeto de informatização).

Uma pesquisa do MIT publicada há alguns anos (FIG 1), comparou o processo de aprendizado de tecnologias industriais e intelectuais, chegando a constatação maior, que nas tecnologias industriais o ensino básico de sua aplicação praticamente cobria toda a 
capacidade oferecida pela tecnologia, permitindo sua adoção plena; o aprendizado em uso embora existisse, era mínimo (CURLEY e PYBURN, 1982). Com as tecnologias intelectuais passava-se justamente o oposto: o ensino básico servia apenas para orientar sua adoção e “manipulação” mais comum, cabendo ao uso efetivo a responsabilidade (a cargo de seu usuário) pelo aprendizado do potencial da tecnologia (em alguns casos indeterminado a priori).

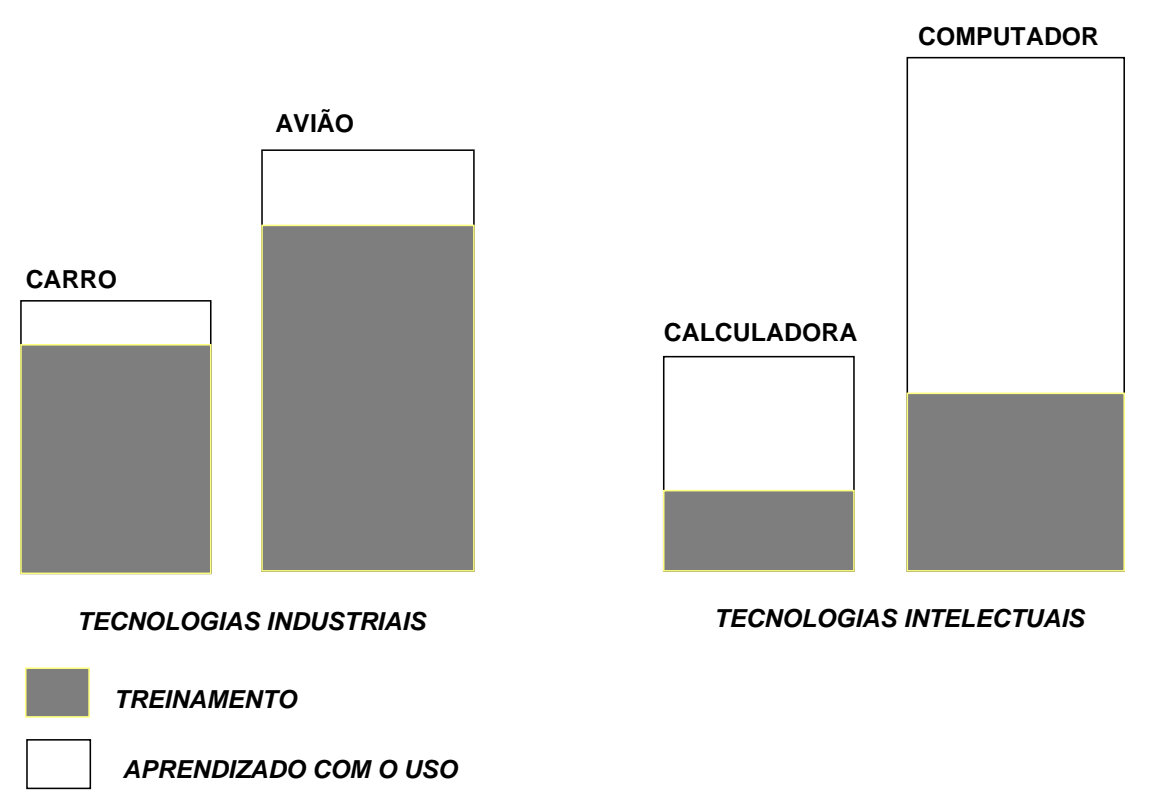

Figura 1 - Aprendizado do potencial da tecnologia

Fonte: CURLEY e PYBURN, 1982. p.36

\section{A Primazia do Algoritmo}

O tratamento da informação por excelência é o cálculo, que encerra em si o conceito de operação, ação organizada e metódica com vistas à produção de um resultado determinado. No entanto, é possível estender a definição de cálculo, além do conjunto de conjunto de operações matemáticas, se forem consideradas outras "ações organizadas e metódicas” como: selecionar, classificar, permutar, combinar, comparar, substituir, transcodificar etc.

O algoritmo se apresenta, desta maneira, como uma seqüência finita (é preciso que o cálculo atinja um resultado) e ordenada (convenientemente disposta para se atingir o resultado desejado) de operações (regras ou instruções), com vistas à resolução de uma determinada classe de problemas (realizando um conjunto de tarefas). 
Uma vez formalizado um algoritmo, pela dissecação de um fenômeno, em seus dados simbólicos e no conjunto de operações sobre estes (algoritmo propriamente dito), corre-se o risco de se perder a percepção global do fenômeno em si, diante do rigor extremo na descrição formal, que por sua vez passa a ser a explicação; o fenômeno, enquanto recorte da realidade, se submete a uma lógica puramente operatória, perdendo eventuais pólos de significação.

Um programa de computador é, portanto, uma equação ótima combinando algoritmo, ou algoritmos, com uma estrutura de dados simbólicos, dentro de um computador, visando a consecução de uma ou mais tarefas, que traduzem um problema.

Em 1936, quase dez anos antes da construção do primeiro computador, o matemático inglês Alan Turing propôs um modelo simples do que seria uma máquina para tratamento de informação, segundo as seguintes premissas (LÉVY, 1987):

- todos os processos passíveis de decomposição em uma seqüência finita e ordenada de operações sobre um alfabeto restrito, que alcançam ao resultado buscado, em um tempo finito, podem ser realizados por uma “máquina de Turing”;

- todos os trabalhos que uma máquina de Turing é capaz de realizar, são algoritmos ou procedimentos efetivos;

- uma máquina de Turing pode se encontrar em um número finito de estados distintos e predeterminados, correspondendo cada estado a uma maneira diferente da máquina reagir às mensagens de entrada;

- para cada problema calculável corresponde ao menos uma máquina Allan Turing (uma tabela de instruções) capaz de resolvê-lo;

- existe uma classe de máquinas, as máquinas universais, capazes de resolver todos os problemas calculáveis ou de realizar todos os procedimentos efetivos; o poder da máquina universal reside em sua tabela de instruções, que lhe permite imitar o comportamento de qualquer máquina particular.

(c) Revista Digital de Biblioteconomia e Ciência da Informação,Campinas, v.6, n. 2, p. 45-70, jan./jun. 2009- ISSN: 1678-765X. 
Em 1945, John von Neumann apresentou uma proposta de construção de uma máquina, que teria registrado em sua memória a tabela de instruções junto com o conjunto de dados para tratamento. Tomava forma a máquina universal de Allan Turing, que pouco tempo depois se materializaria no primeiro computador. Vale salientar algumas características da “máquina universal”, arquétipo do computador, de interesse para esta reflexão (LÉVY, 1987):

- potência de todos os possíveis, com a vocação de abarcar e recapitular a totalidade, mesmo o que dela ainda não se manifestou; como uma imagem, uma analogia, basta observar o que se passou na arte e na literatura ocidental neste século, sob a ação da idéia motriz da Razão Moderna, a máquina universal;

- artistas e escritores abandonam a tradição, que procuravam manter e evoluir pela sua reinterpretação, e passam a recapitular todos os estilos, de todas as épocas, de todos os países; não se criam obras, mas sistemas de obras, “máquinas” produtoras de obras, sempre reinventadas;

- uma parte significativa da criação artística contemporânea se concentra, sobre as causas eficientes, materiais e formais, em detrimento da causa final (segundo a teoria das quatro causas de Aristóteles);

- artista nesta Sociedade da Informação, não quer ser reduzido a uma matriz formal, ele quer passar ao nível lógico superior, definir uma nova "linguagem”, para não ser ultrapassado pela máquina;

- trabalho formal (operatório) sobre sinais;

- a máquina universal deixa de fora toda consideração sobre a significação ou a interpretação dos sinais ou símbolos que opera;

- só um ser humano, atuando como observador consciente, e não como mero periférico desta máquina, pode interpretar ou projetar alguma significação sobre um sistema formal; 
- a sensação serve ao conhecimento do universo objetivo, que cada vez mais se fragmenta em diminutos átomos, registrados sob uma codificação impalpável;

- o objeto pulverizado, representado por dados simbólicos elementares sobre os quais trabalha a máquina universal, está muito abaixo do patamar da percepção imediata;

- novos dispositivos para captura digital não apreendem uma forma global (no sentido platônico), mas apenas uma imagem, um padrão, uma medida, traduzida em uma seqüência de impulsos binários;

- os objetos, os processos, as palavras são decompostas, analisadas, tratadas pela informática, em um nível tão pequeno, que não há mais para nós imagem diretamente perceptível, somente uma série interminável de ocorrências de símbolos, células, pixels, átomos de circunstâncias, que se opõem aos elementos macros e micros de nossa vida ordinária, com seus nomes, suas coisas e suas unidades de sentido imediatamente sensíveis;

- a dissolução do objeto global e intuitivamente sensível acompanha a informatização; correlativamente, o sujeito, que entretinha relações de conhecimento e ação com as coisas, cede seu lugar a um programa e uma base de dados: uma série de operações elementares sobre dados simbólicos, codificadas como algoritmos;

- a "máquina universal” operando formalmente sobre um universo pulverizado de símbolos elementares, digita(liza)dos como dados simbólicos, se apresenta como um esquema abstrato proveitoso no domínio da técnica e da arte.

\section{Uma breve interpretação histórica da instituição do cálculo}

Que história, singular ao Ocidente, foi capaz de conjuminar processos que deram forma a filha pródiga da Razão Moderna, a máquina universal? Por que caminhos o “algoritmo instrumental” insinuou-se em todo fazimento humano, culminando na sua mais perfeita encarnação, o computador? Estas questões merecem uma abordagem mínima. 
A lenta gestação do que foi denominado “cálculo”, pode ser ilustrada a partir de posições filosóficas, científicas e técnicas contemporâneas, como: a cristalização de uma visão de mundo assentada na lógica matemática, oferecida pelo primeiro L. Wittgenstein no inicio deste século, a cibernética do final dos anos 40, e a teoria da informação da mesma época (LÉVY, 1987).

As matemáticas gregas operam um verdadeiro “corte epistemológico” sobre as anteriores, por sua abstração. Os pontos, retas, superfícies e volumes considerados são figuras ideais, independentes de todo substrato material. O triângulo desenhado sobre o solo serve para ilustrar a demonstração ou estimular a imaginação, mas fica claro que não é sobre ele que se argumenta. Visando as relações e proporções, a Razão encara as figuras independente de valores numéricos. A geometria grega é teórica, no seu sentido original de contemplativa. Pode-se afirmar que os gregos não inventaram a geometria como a conhecemos atualmente, mas a verdade geométrica, pautada na necessidade de demonstrar, de mostrar compreensão enquanto seus contemporâneos objetivavam a utilidade dos cálculos.

A demonstração matemática entre os gregos, era assemelhada a retórica, como uma modalidade de persuasão, legitimada por uma sociedade fundada em um ideal de democracia, de comunidade de iguais. Seu sentido, como da justa retórica, não era falsificar a verdade por uma “roupagem” de sofismas, mas enaltecê-la, elevá-la a sua dimensão absoluta. O teorema se firmava como a única certeza intangível que um homem livre pode aceitar, pois está fundada no Logos.

Os gregos, desta forma, transubstanciaram tudo o que era naquela época meio de cálculo, em modelo de inteligibilidade racional. Esta mutação está na origem da Ciência, e desde a época de Platão, o esforço para descobrir uma coerência explicativa do real sob a desordem dos fenômenos se identifica com a investigação de estruturas matemática subjacentes.

Os Elementos de Euclides, por muito tempo, permaneceram sendo um modelo de teoria dedutiva, onde todos os termos e proposições se encontram definidos, salvo os axiomas e postulados. Somente no século XIX os matemáticos reconheceram falhas na arquitetura euclidiana, o que deu um outro rumo a noção de teoria dedutiva, de axiomática: passou a 
ser menos importante demonstrar a verdade categórica de certas proposições, do que construir sistemas perfeitamente coerentes.

O interesse se deslocando para questões de não contradição e de estrutura interna de sistemas, os axiomas passam a assumir a posição de hipóteses, de convenções, além do verdadeiro e do falso. Pode-se fazer uma ligação desta mudança radical, com alguns dispositivos culturais que começam a se instituir no Ocidente: o abandono da referência religiosa (“Deus está morto...”), o interesse antropológico emergente de estudo “científico” de outras civilizações, promovido pelo colonialismo, e a exploração de idéias a partir do reconhecimento da relatividade histórica dos valores.

Eliminado todo apelo à intuição nas construções matemáticas, estas, por sua vez, dissociadas da consistência lógica exigida pela verdade categórica, as matemáticas paradoxalmente se engajam na via do rigor crescente (rigor mortis?). Substituem-se nestas construções as palavras da linguagem usual, por símbolos “virgens” de sentido, e por conseguinte suscetíveis de receber exata e exclusivamente aquele sentido que os axiomas lhes conferirem.

A especificação das regras segundo as quais devem ser conduzidas as deduções válidas, constitui a etapa seguinte dessa formalização. Explicitadas, as regras de lógica se tornam por sua vez hipotéticas e convencionais, como os axiomas; levando a demonstração de um teorema em um sistema formal a ter a aparência de uma transformação regrada de configurações de símbolos, de manipulação de signos tipográficos seguindo procedimentos exatamente definidos. A evidência dos encadeamentos lógicos não tem mais lugar na dedução, travestida em um estrito jogo formal.

Por uma volta inesperada, a demonstração sofre uma metamorfose e vira cálculo, algoritmo “cego” mas eficaz, manipulação de símbolos em um plano virtual, abstrato e “purificado”, que distingue a Razão Moderna ocidental de qualquer outra (LÉVY, 1987):

- a semântica de um sistema formal concerne as interpretações concretas que dele se podem fazer; intrinsecamente desprovido de significado, o sistema formal se presta a por em evidência isomorfias estruturais entre domínios concretos aparentemente sem relações; ou seja, a mesma axiomática pode formalizar várias teorias ou modelos; 
- a sintaxe de um sistema formal se relaciona unicamente a suas características internas; dentre as propriedades sintáxicas destacam-se a consistência, a completitude e “decidibilidade":

- o sistema é consistente se não contém fórmulas que não possam ser derivadas de seus axiomas;

- a completitude ecoa o princípio do terço excluso; ou seja dada uma expressão bem formada do sistema, deve-se poder demonstra-la com falsa ou verdadeira;

- a “decidibilidade" exige um método que possa distinguir entre proposições demonstráveis (ou refutáveis) e outras.

Coube ao matemático Gödel, em 1931, a responsabilidade por abalar definitivamente esta formalização progressiva, ao demonstrar que um sistema formal suficientemente poderoso para codificar a aritmética seria incompleto. Pondo um termo na ambição dos matemáticos formalistas de "codificar” a matemática e o mundo, em sistemas formais dedutivos, perfeitamente coerentes.

Foi justamente abordando a questão da “decidibilidade” que A. Turing elaborou o modelo de autômato universal, em seguida batizado de máquina de Turing. A perfeita definição de algoritmo que ele alcançou nesta tentativa, reforçou a demonstração de Gödel, ao mesmo tempo que assentava as bases teóricas da informática, através da máquina universal. Fato que o levou a participar ativamente da construção de protótipos de computador, na Inglaterra da década de 1940.

Desta breve exposição percebe-se uma linha quase contínua que religa: a descoberta, há mais de vinte séculos, de um espaço totalmente abstrato, a exigência grega da Razão, as investigações lógico-matemáticas dos últimos cento e cinqüenta anos e, finalmente, a concepção do computador moderno. Na gênese de uma ordem dedutiva perfeita, e, portanto, de um modo de pensar diáfano, mais transparente ao esplendor da Razão, emerge o algoritmo rigoroso, que paradoxalmente faz seu "ninho" em um autômato “cego”, que privilegia o poder operatório, a velocidade, a instrumentalidade. O ideal grego volta a ser subjugado à visão utilitarista da matemática pré-pitagórica, da 
contabilidade renascentista, da ciência do Estado - a estatística, da filosofia analítica deste século.

Toda a informática repousa sobre a descoberta que processos físicos podem ser exatamente isomorfos à operações lógicas. Este princípio teve uma formulação original em uma tese de doutoramento de 1938, defendida por Claude Shannon, o mesmo da teoria da informação. Nesta tese, C. Shannon demonstrava a analogia de estrutura entre o funcionamento de circuitos elétricos e a álgebra de Boole. A concepção de componentes dos computadores segue ainda hoje os princípios fundamentais expostos por C. Shannon (LÉVY, 1987).

Uma genealogia da informática deve reconhecer não somente sua origem na lógica aristotélica, enquanto um instrumento intelectual autônomo, capaz de nutrir uma reflexão filosófica diante do domínio teológico da Idade Média, como na lógica moderna que emerge especialmente nos trabalhos de Gottfried Leibniz. De fato, um lugar especial deve ser reservado ao projeto leibniziano de construção de uma característica universal.

Apesar do avanço progressivo, dentro dos enunciados da Lógica, no uso de varáveis simbólicas em lugar de termos concretos, ao longo da época clássica e medieval, a linguagem natural ainda predominava à época de G. Leibniz; ou seja, um mesmo raciocínio poderia ser expresso de várias maneiras diferentes.

Respondendo a um ideal de univocidade lógica e influenciado pela filosofia e escrita chinesas, G. Leibniz expôs pela primeira vez os princípios de uma escritura ideográfica, única capaz de expressar de forma direta as idéias, sem passar pelo intermediário fonética - a característica universal.

Segundo G. Leibniz, a álgebra representava uma modelo de escritura racional, com o inconveniente de só se aplicar aos números. Portanto, fazia-se necessário uma “álgebra geral”, uma linguagem filosófica que permitisse a expressão de todas idéias, de forma tal, que não mais existiriam disputas metafísicas ou morais; estas seriam resolvidas por um “cálculo”. Enunciava-se assim um percurso da moderna lógica matemática. 
Decorrente da característica universal, como sua vertente operatória, G. Leibniz propôs o calculus ratiocinator, recuperando das matemáticas seu poder de operar sobre símbolos segundo procedimentos exatamente especificados, mas estendendo este poder além do domínio da quantidade. Para G. Leibniz, um cálculo só pode ser feito sobre uma característica, um sistema de signos visíveis cujas combinações e transformações estão sujeitas a regras sem ambigüidade. Naturalmente, este projeto culminou com sua tentativa de construir uma “máquina de raciocinar”, que não teve condições de se realizar com os recursos mecânicos da época.

As linguagens de programação da informática “realizaram” (com restrições significativas) o sonho de G. Leibniz, culminando o avanço em lógica matemática na linha reducionista que substitui as incertezas da Razão, pela infalibilidade do cálculo, do sistema formal e coerente de signos sobre o qual opera um conjunto de instruções.

Neste somatório de influências que governou o destino da informática coube a cibernética uma contribuição ímpar: na concepção dos primeiros computadores, na fundação das bases da inteligência artificial, na introdução dos conceitos e do formalismo lógicomatemático nas neurociências, e mais que tudo, na disseminação de um complexo de idéias, conjugando as noções de sistemas, de informação, de comunicação e de cálculo.

O movimento fundador da Cibernética nasceu em 1943, com a publicação de dois artigos clássicos (BRETON, 1995):

- “Comportamento, meta e teleologia”, do matemático Norbert Wiener, do fisiologista Arturo Rosenbluth e do engenheiro eletrônico Julian Bigelow; sobre uma possível base de analogia entre os seres vivos e as máquinas, explica o comportamento animal pela causalidade circular que religa os organismos e seu ambiente (o famoso feedback); o inextricável problema da teleologia do ser vivo começa a ter uma solução mecanicista;

- "Um cálculo das idéias imanente à atividade nervosa”, do neuropsiquiatra Warren McCulloch e do matemático Walter Pitts; identifica o sistema nervoso a uma máquina lógica e mostra que uma rede de neurônios formais (simplificados) possui o mesmo 
poder de cálculo que uma máquina universal de Turing; estão fixados os critérios que doravante irão determinar o estudo do processo cognitivo.

O movimento da Cibernética foi marcado pelo selo da lógica matemática desde sua origem. Seu principal pensador, N. Wiener, além de ter estudado em Cambridge com Bertrand Russell, afirmava categoricamente que o mesmo impulso intelectual que levou ao desenvolvimento da lógica matemática conduzia ao mesmo tempo à mecanização ideal ou real dos processos do pensamento. Da mesma forma, é possível identificar nos demais fundadores do movimento, a primazia de uma visão do mundo centrada na lógica matemática, em suas formações ou em suas posições a partir da constituição do movimento.

Fundados na lógica matemática, todos esses pioneiros teóricos da informática militavam dentro de um enfoque que buscava reconhecer no ser humano e nas coisas, um "ser informacional”. Esperavam descobrir a uma essência de natureza informacional, transparente e racional, que se destacaria de um fundo de “ruído” (diabólico, segundo N. Wiener).

Este modelo informacional sobressai particularmente no pensamento de N. Wiener, que se empenha em operar uma separação bem nítida entre a dimensão informacional, única essencial para ele, e os suportes materiais, secundários e sem importância. N. Wiener chega mesmo a imaginar e propor, já nesta época, que este modelo poderia se “encarnar” em uma máquina computacional, e até mesmo ser transmitido como uma mensagem entre máquinas (BRETON, 1995).

A noção de informação, defendida pela Cibernética (enquanto uma teoria comunicacional), foi enriquecida por C. Shannon, N. Wiener e A. Turing, durante a década de 1940. Eles aportaram contribuições independentes, mas similares, onde se tendia paradoxalmente a uma sutilização e a uma coisificação da informação. A primeira tendência, alimentada por uma metafísica do "ser informacional” e a segunda, pela formulação estatística de suas formas de mensuração.

Os caminhos da lógica e da teoria da informação se entrecruzam antes mesmo de suas formalizações modernas, quando então se interligam ainda mais, através dos conceitos de operação e de codificação: 
- quanto ao conceito de codificação, após G. Leibniz, e mais intensamente após Frege, a lógica começa a se "aprisionar” dentro de uma visão que prima pela otimização da codificação, e que tende a produzir uma linguagem monosêmica, instrumento ideal para comunicação; não se deve desprezar também as possíveis influências que foram aportadas por Turing e C. Shannon, por conta do trabalho que participaram, sobre decifração de códigos secretos (criptografia), durante a segunda grande guerra;

- quanto ao conceito de operação, pode-se tomar a assertiva de C. Shannon, de que informação é aquilo que permanece invariante sob todas as codificações ou traduções invertíveis, que podem ser aplicadas às mensagens produzidas por processos; ou seja, dado um tradutor que opera sobre uma mensagem. se a tradução é revertível, sua saída contém a mesma informação que a sua entrada; a informação é, portanto, o que permanece invariante por uma série de operações revertíveis; a comunicação passa a ser um caso particular do cálculo: uma série de operações cujo sentido pode ser invertido de tal forma que os dados iniciais possam ser reencontrados.

Como foi dito, a lógica matemática foi revitalizada por uma associação à teoria dos autômatos, pela Cibernética e pela Teoria da Informação. N. Wiener afirmava que a Ciência de hoje é operacional, ou seja que ela considera cada proposição como essencialmente referente às experiências possíveis ou aos processos observáveis; desta maneira o estudo da lógica deve se reduzir ao estudo da máquina lógica.

O já citado artigo de N. Wiener de 1943, fundador da Cibernética, é exemplar a este respeito, ao adotar uma leitura dos fenômenos, que pode se denominar de “caixa preta”, onde se privilegia a lógica do fenômeno, passível de se depreender a partir de uma análise da estrutura de comportamento expressa no próprio fenômeno; de sua funcionalidade, refletida nas relações entre entradas e saídas. A essência de um fenômeno qualquer seria, portanto, a organização dos cálculos entre informação aferente e informação eferente.

Esta proposta de máquina universal, um novo “campo unificado” de uma pretensa "teoria de tudo”, assentada em termos de cálculo e informação, se oferece como um novo paradigma tecno-científico, capaz de aportar respostas inovadoras a questões clássicas, do tipo: conhecimento, sabedoria, ser, teleologia, memória, percepção, cognição etc. 


\section{Premissas Filosóficas}

A grandeza da filosofia de L. Wittgenstein reside tanto na sua profunda reflexão sobre essência e aparência, assim como pela sua precedência e contribuição na criação de um novo imaginário; uma nova fundação metafísica para este século, interpretada e apropriada (bem ou mal) pela filosofia analítica, e com forte ascendência sobre as premissas filosóficas da grande metamorfose cultural representada pela atual informatização da Sociedade.

Sem qualquer pretensão de desenvolver uma exegese do pensamento de L. Wittgenstein, é preciso, no entanto, estabelecer alguns pontos para uma compreensão mesmo que superficial desta filosofia maior, orientadora da nova configuração ontológica da informática enquanto tecnologia, processo e imaginário. É preciso tentar ilustrar a precessão deste imaginário radical sobre o movimento da informática, e deste último sobre o atual desenvolvimento das ciências humanas, seus métodos e suas técnicas.

Começando pelo conceito de fato, constata-se, neste século, sua ascensão a uma centralidade, sob a qual é possível notar uma certa ideologia: o mundo e as coisas no mundo são completamente neutras com respeito a significado e valor. A mente humana pode impor tais significados e valores no mundo externo (lá fora), mas em si mesmos, o mundo e as coisas do mundo simplesmente existem se quaisquer finalidades ou qualidades de bom, mal, belo, consciência, ou significado.

Esta visão, com precedentes na história, teve neste século um dado adicional a mais: a crença de que as verdades sobre o mundo natural podem ser afirmadas pela simples percepção sensorial refinada, ajudada pela inferência lógica. Ou seja, com a separação entre fatos e valores, só o conhecimento empírico dos fatos sobre o mundo, se afirma como critério, pelo qual um homem será capaz de orientar-se com respeito a sua investigação científica, e até sua conduta na vida. Parece claro que sob esta visão, existe o pressuposto da imparcialidade, de que o ser humano pode observar a realidade livre da influência de seu corpo e de suas emoções, enfim, de qualquer condicionamento (BRETON, 1995).

(c) Revista Digital de Biblioteconomia e Ciência da Informação,Campinas, v.6, n. 2, p. 45-70, jan./jun. 2009- ISSN: 1678-765X. 
L. Wittgenstein e M. Heidegger, cada qual de sua maneira, "re-injetaram" na intelectualidade contemporânea, a idéia de dois mundos, junto com a indicação que o mundo por trás das aparências não pode ser "visto": toda olhar contém uma visão implícita e imanente. L. Wittgenstein procura separar os dois mundos (por ele denominados: mundo da linguagem e mundo do silêncio), praticando esta incisão por meio de uma atenção especial à linguagem, segundo ele, idêntica ao pensamento, e, até certo ponto, ao comportamento no mundo. Para o cientista, L. Wittgenstein revela a antinomia entre a estrutura lógica do mundo ideal, que sua linguagem científica construiu, e a vida fragmentada e desconexa que sua linguagem ordinária verdadeiramente o faz viver. L. Wittgenstein ataca a ilusão de que as questões fundamentais de significado e finalidade podem ser resolvidas pelo intelecto ordinário, demonstrando que os problemas da filosofia estão justamente enraizados em confusões de linguagem, ou seja, em uma mistura de "níveis de realidade”.

O Tratado Lógico-Filosófico (doravante denominado Tratado), sua única obra publicada enquanto era vivo, em 1922, incorpora a idéia do mundo numenal, por meio de uma seqüência de proposições, aparentemente lógico-científicas, a respeito do instrumental pelo qual o homem conhece o mundo fenomenal.

O que é este instrumental? É a linguagem, considerada como o pensar. Em outras palavras, a essência da linguagem é o pensamento, e este é a mesma coisa que lógica, enquanto conjunto de regras, estrutura transparente a si mesma, constituída por si mesma. Através da linguagem a mente organiza a si mesmo e ordena os dados de uma observação qualquer, científica ou não. Desvendando-se esta estrutura lógica da linguagem, pode-se reconhecer a estrutura lógica do mundo. Trata-se de um trabalho interior, um verdadeiro projeto de libertação, uma “revolução" no sentido etimológico do termo (NEEDLEMAN, 1983). L. Wittgenstein mostra que a lógica não só estrutura o mundo que vivemos como também o intelecto, ele próprio. A Ciência, por conseguinte, desenvolve observações que tomam a forma de fatos, obedientes a leis (regras lógicas?), pois tudo que é conhecido é por definição estruturado pela lógica.

Desta maneira, a lógica não nos diz nada sobre o mundo: trata-se apenas de um conjunto de regras, pelas quais se pode “conhecer” o mundo, regras pelas quais organizam-se as observações registradas pelos sentidos. Este “conhecimento” existe na forma de 
proposições; afirmações que têm uma forma inevitavelmente lógica e que funcionam como uma espécie de modelo do mundo. As categorias de pensamento de Kant se transformam no pensamento de L. Wittgenstein, em “proposições” lógicas, determinantes a priori do ser-no-mundo. A meta de uma autêntica filosofia é dar significado ao infalável pela apresentação clara do falável.

A mensagem que transparece no pensamento de L. Wittgenstein é que tudo que chamamos pensamento, especialmente depois do domínio da Razão Moderna ocidental, pode ser feito por uma máquina: a maneira de pensar os fenômenos, máquinal $e$ maquinante, só admite como categorias de pensamento a lógica, o cálculo (o algoritmo), a comunicação, a informação, o dado...

Segundo esta visão de conformidade entre mundo, pensar, linguagem e lógica, L. Wittgenstein faz coincidir a solução de um problema com a exposição do procedimento efetivo ou do algoritmo capaz de resolvê-lo: “cada questão que se pode absolutamente resolver pela lógica, deve poder se resolver, sem mais” (Tratado $5.551^{1}$ ). Este é o universo estruturado pelo processo de informatização, em correspondência direta com um sujeito transcendental em forma de autômato finito.

A lógica, co-extensiva ao mundo, é para L. Wittgenstein a verdadeira essência da comunicabilidade. Afirmar que o mundo é lógico, acima de tudo é afirmar sua transparência ao Logos (“Não saberíamos pensar nada ilógico, porque então nos seria necessário pensar ilogicamente” - Tratado 3.03). Dado o estrito paralelismo, estabelecido entre fatos e proposições, aproximam-se assim as noções de processo e de cálculo. Desta forma, o pensamento, o simbolismo, os objetos materiais, os processos físicos, os artefatos, são todos reunidos sob a estrutura lógica, no mesmo plano dos fatos ("O mundo é o conjunto dos fatos, não das coisas” - Tratado 1.1).

Este mundo de "tudo que sucede”, o mundo dos eventos, é o da teoria da informação, que não tem interesse pelo significado dos símbolos mas por sua simples ocorrência. Uma ciência articulada pela teoria da informação, pressupõe a existência de um universo de eventos descritíveis e traduzíveis. Um evento, um “estado de coisas”, uma ocorrência, um

1 Referência normalmente adotada quando se mencionam as proposições do Tratado (L. Wittgenstein, 1922). 
fato, uma decisão, se observa, se transmite, se apresenta como uma definição operacional, portanto imaterial, que pode se medir, mas não tem dimensão.

A atribuição de imaterialidade à informação, sem ser de todo correta, tem o risco de introduzir o erro clássico da dualidade cartesiana, mente e extensão; um bit não é nem uma partícula de matéria, nem um elemento de idéia, é um átomo de circunstância. Uma ciência que analisa seus objetos do ponto de vista da informação, parte de uma visão do mundo como "tudo o que sucede", em uma certa medida a disposição fundada pelo Tratado. De fato, para L. Wittgenstein, as proposições, são também fatos, e estão religadas aos fatos que elas representam em uma identidade de estrutura, constituindo o próprio pensamento o quadro lógico dos fatos. O pensamento é portanto de essência fatual, como o resto de “tudo que sucede”. A essência do mundo é aquela de toda descrição: lógica, ou nos termos mais atuais, informacional.

Partindo da metafísica de L. Wittgenstein, os fundadores da informática a traduziram a seu grado, em projeto de constituidor e instituidor de um mundo sem paradoxo, inteiramente lógico e descritível. Um mundo de informação, onde se é levado à constatação e ao ideal, dentro deste projeto de informatização da Sociedade, em curso, de uma nova “u-topia cibernética”, onde não há lugar, onde se afirma a inutilidade de um sujeito pensante, representando este mundo. Paradoxo da alta modernidade: sem sujeito pensante, quem enuncia as proposições que projetam a “u-topia”? quem as entende? quem utiliza esta codificação?

O descaminho das teorias da chamada "primeira cibernética” (1943-1953), a partir do pensamento de L. Wittgenstein, é muito claro em certos pontos cruciais, como também nas interpretações que determinaram certos desdobramentos desde a filosofia analítica. Primeiramente, se L. Wittgenstein não reconhece um sujeito metafísico no mundo, pelo menos o estabelece em seus limites, e até mesmo o identifica com o próprio mundo: "Eu sou meu próprio mundo” - Tratado 5.63. Esta visão, encerrando no sujeito todo o universo informacional, está nos antípodas da conceituação de informação, informática e cibernética, de N. Wiener e W. McCulloch.

Coube a denominada “segunda cibernética”, originalmente animada por Heinz von Foerster, o ensejo de dar alguma expressão à noção de sujeito-mundo de L. Wittgenstein. 
A partir do reconhecimento de que a simples retroação não esgota a circularidade do processo biológico, buscou-se uma compreensão dos processos de autoreprodução, autoreferência e auto-organização. Não é suficiente dizer que se um ser vivo age sobre seu ambiente, ele percebe em retorno os resultados de sua ação: o ser vivo, enquanto conduzido por um processo cognitivo organiza o que é para si o mundo; “calcula” uma realidade no interior das imposições de seu sistema nervoso, da disposição de seus captores sensoriais, de sua experiência passada etc (BRETON, 1995).

Sua ação, no sentido pleno do termo, sobre seu ambiente é ao mesmo tempo percepção, organização e elaboração do que é, para si, a realidade; e é em função desta realidade “calculada” que o ser vivo vai re-perceber, re-organizar e re-elaborar o que será seu mundo próprio, e assim indefinidamente. A auto-organização se apresenta, desta forma, como um processo circular infinito, coincidindo a organização de si com organização da realidade.

Portanto, o universo exterior não pode conter a menor informação. A noção de informação só pode mesmo ter sentido no interior do mundo do sujeito. Nesta linha de investigação, é que os biólogos Humberto Maturana e Francisco Varela, vem oferecendo uma instigante conceituação sobre o processo cognitivo, dentro do que apelidaram de autopoiesis: a construção de si mesmo e da realidade que o cerca, ou em outras palavras, o nível de ser determina o mundo em que se vive (MATURANA e VARELA, 1997).

Outra parte do pensamento de L. Wittgenstein que não teve desdobramento dentro de uma epistemologia da informática, foi a que se refere ao “indizível”, ao inexprimível; aquele mundo que é invocado na última proposição de sue Tratado: “O que não podemos falar, devemos silenciar" - Tratado 7. Assim o mundo de "tudo o que sucede", do "que pode ser dito", exclui por baixo nosso "meio de vida”: o espaço, as cores, os sons, as linguagens formando as mídias, os veículos para eventuais mensagens, enfim toda a “espessura” sensível do mundo; e, exclui pelo alto aquilo porque vivemos e todas as significações e valores em geral. O elemento "inexprimível”, vasto e profundo, é o "sertão grande”, que nos lembra Guimarães Rosa. O mundo estritamente calculável e comunicável se reduz a uma fina película do ser, a dos eventos (fatos), percorrida pelo jogo das traduções e das operações.

(c) Revista Digital de Biblioteconomia e Ciência da Informação,Campinas, v.6, n. 2, p. 45-70, jan./jun. 2009- ISSN: 1678-765X. 


\section{O Paradigma Informático}

O emprego crescente de conceitos informáticos e cibernéticos nas diversas disciplinas, o uso intensivo de processos de modelagem e de simulação para estudar os fenômenos físicos ou humanos, ou a tendência ao "aprofundamento” do método científico pela formulação de sua cadeia de pensamento por meio de algoritmos são algumas das manifestações da emergência de um “paradigma da informática”.

Não se trata de um paradigma assentado apenas sobre um corpo de doutrina sistemática, tendo seus partidários e adversários declarados. Mais do que isto, vem se apresentando também como uma postura intelectual, alimentada por metáforas (processo, entrada, saída, memória etc.), procedimentos e hábitos de investigação. A própria utilização crescente de tecnologias da informação e de sistemas de informação ou de apoio à decisão vem favorizando a infiltração deste paradigma na cultura da "alta modernidade”.

Algumas interrogações se impõem de imediato: na vertente ontológica, a redução do mundo ao que dele se apreende como informação, e a representação de sistemas físicos, viventes ou psíquicos como máquinas de tratamento de informação; na vertente metodológica, a velha questão a respeito da primazia de uma única racionalidade científica, codificável, programável e aplicável a todas as situações e coisas, e também a indagação a respeito da finalidade da atividade científica, voltada para prever e calcular sempre melhor ou para tornar mais inteligível e claro o mundo que nos cerca, uma ciência para manipulação ou para compreensão, como definido em Schumacher (SCHUMACHER, 1973).

Começando esta análise pela insinuativa e freqüente prática de modelagem e de simulação com uso da informática, percebe-se de pronto sua incontestável adoção nos campos mais diversos das ciências, e até do jogo e do entretenimento. O que logo sobressai desta iniciativa é o fator legitimador do aparato técnico-científico adotado e sua capacidade de facilitar e de conferir um caráter experimental, naturalmente ausente em algumas disciplinas.

De fato, por se tratarem de modelos e simulações sobre estes modelos, não se pode qualificar isto como uma experiência científica. No entanto, deve-se ter mente que a 
experiência científica clássica já opera de uma certa forma, uma abstração, uma construção artificial do objeto de estudo. Logo, nada impede que se considere a simulação digital como um grau suplementar na idealização do fenômeno, visando ainda mais sua purificação e controle.

O extraordinário poder de cálculo estatístico e de análise de dados, aliado à capacidade de modelagem de dados, ambos ofertados pela informática, imprimem uma funcionalidade ímpar à simulação digital, reforçando o caráter empírico e indutivo da investigação informatizada. Legitimam-se tratamentos sofisticados e complexos sobre um grande volume e um diversificada gama de dados, na tentativa de forçar a emergência de informações, de fazer “os dados falarem por si mesmos”...

Como um cálculo, por natureza discreto, pode sustentar a simulação de um processo, essencialmente contínuo? De fato, os limites à precisão digital persistem ainda, por mais estendidos que sejam a cada geração tecnológica, obrigando qualquer simulação a aplicação de ajustes compensatórios. Da mesma maneira, a simplificação, com risco reducionista, ainda se faz necessária na modelagem e na simulação digital, o que a distancia da realidade do fenômeno, que pretende modelar, submetido a uma profusão de detalhes e influências.

A linguagem de modelagem, de descrição do fenômeno, geralmente de natureza matemática ou estatística, "reveste” o objeto de estudo com uma aura científica, ao mesmo tempo que o “cristaliza” dentro de uma rede de pressupostos, formalizando um “engenho investigador”, com estímulos e respostas previsíveis. O que não impede que o pesquisador se surpreenda com as respostas obtidas, especialmente quanto mais obscuras tenham sido as questões colocadas originalmente (LÉVY, 1987).

A informática se impõe como instrumental por excelência, promovendo um ferramental matemático e estatístico sofisticado, dando acesso à simulação de modelos digitais, contribuindo largamente na formalização dos procedimentos de pesquisa e investigação, e, conferindo um caráter inédito de rigor e de exatidão às ciências. A informática ofereceria, portanto, muito mais do que um artefato científico: o recurso de um método único, tão ambicionado pelos positivistas desde o século passado. Ofereceria um engenho, um operador metacientífico, capaz de fazer passar uma disciplina qualquer, de 
um estado discursivo, qualitativo e pré-científico, a um estado matematizado, quantitativo e científico.

Esta pretensão é fortalecida (e também fortalece) tanto pelo matematismo subjacente ao processo, em curso, de informatização da Natureza (vide capítulo anterior) e da Sociedade, como pelo logicismo subentendido na formalização da racionalidade científica por meio de algoritmos. Fundamenta-se o programa de um saber capaz de constituir seu objeto como processo em si independente do sujeito, enquadrado sobre um referencial espaço-temporal universal e privado de mistério, consignado a categorias indiscutíveis e unívocas, expresso em uma linguagem matemática ou estatística de potencial ilimitado, cuja pré-adaptação miraculosa ao fenômeno, e a coerência interna não parecem provocar questões.

Começando pela definição dos dados iniciais, que cada vez mais obedece um procedimento direta ou indiretamente informatizado, passando pelo algoritmo que opera os símbolos que representam estes dados, e não seus significados imediatos e informais, e chegando aos resultados rigorosamente expressos em uma linguagem congruente o código simbólico dos dados, a "programação" da racionalidade implica sempre, ao longo deste percurso, a classificação, a codificação e a organização de todos os dados simbólicos, que traduzem as descrições dos fatos relativos ao objeto de estudo.

A informática que pode ser utilizada para qualquer fim, teria assim uma perfeita neutralidade? Esta é uma questão que parece ter sido respondida neste percurso, ficando de certa forma bem claro, que a tecnologia da informação, enquanto instrumental de um processo de informatização, carrega consigo e realiza a filosofia sob este processo. Uma filosofia onde predomina a postura indutiva, a Razão instrumental e o logicismo, em que o modelo operativo é o que apreende e responde melhor à ontologia informacional. 
A informática como encarnação atual da "máquina universal”, como corporificação da Razão Moderna, se desenvolve e se aprimora dia a dia na representação mais perfeita desta máquina, e se caracteriza progressivamente como o instrumental único do método científico, permitindo e estimulando a matematização de qualquer fenômeno, fórmula primaz de “elucidação" de sua estrutura fundamental, de sua essência. No debate epistemológico em curso, a informática ressuscita a proposta de unificação metodológica do positivismo; o campo do método científico único é pela primeira vez efetivamente reforçado com os meios mais encantadores e “positivos” para sua ambições.

\section{Referências}

BADIOU, A. Le concept de modèle. Introduction à une épistémologie matérialiste desmathématiques. Paris: Maspero, 1969.

BARDINI, T.; HORVATH, A.T. The social construction of the personal computer user. $\mathbf{J}$ Commun, Austin, v.45, n.3, p.40-65, 1995.

BAREL, Y. Propos de travers ou la transversalité, in Lucien Sfez (dir.), dictionnaire critique critique de la communication. Paris: PUF, 1989.

BARRETT, W. The illusion of technique. New York: Doubleday, 1978.

BOUGNOUX, D. Introdução às ciências da informação e da comunicação. Petrópolis: Vozes, 1994.

BOUGNOUX, D. Novas formas de se estar junto. Correio da UNESCO, Rio de Janeiro: FGV, 1995.

BRETON, P. Histoire de l’informatique. Paris: La Découverte, 1987.

BRETON, P.; PROULX, S. L'explosion de la communication. La naissance de une nouvelle idéologie. Paris: La Découverte, 1989. 
BRETON, P. Le sens des mots: l'apparition des termes 'informatique', 'ordinateur' et 'information'. In: TINLAND, F. (ed.) La techno-science en question. Seyssel: Champ Vallon, 1990.

BRETON, P. À l’image de l'homme: du Golem aux créatures virtuelles. Paris: Seuil, 1995.

CURLEY, K.F.; PYBURN, P.J. Intellectual tecnologies: the key to improving whitecollar productivity. Sloan Manage Rev, Cambridge, v.24, n.1, p.31-39, Fall 1982.

DELACAMPAGNE, C. Histoire de la philosophie au XX Siécle. Paris: Seuil, 1995.

ESCARPIT, R. L’information et la communication: theorie generale. Paris: Hachette, 1991.

FREDERICK, H. Computer networks and the emergence of global civil society. In: HARASIM, L.M. (ed.). Global Networks: computers and international communication.. Cambridge: MIT Press, 1993.

FRIEDMANN, G. Sete estudos sobre o homem e a técnica. São Paulo: DIFEL, 1968.

LALANDE, A. Vocabulaire technique et critique da la philosophie. Paris: PUF, 1993.

LAND, F. Is an information theory enough? Comput J, London, v.28, n.3, p.211-215, 1985.

LANGEFORS, B. Theoretical analysis of information systems. 4.ed. Philadelphia: Studentlitteratur Auerbach, 1973.

LEÃO, E.C.; et al. A máquina e seu avesso. Rio de Janeiro: Francisco Alves, 1987.

LÉVY, P. La machine univers: creation, cognition et culture informatique. Paris: La Découverte, 1987.

(c) Revista Digital de Biblioteconomia e Ciência da Informação,Campinas, v.6, n. 2, p. 45-70, jan./jun. 2009- ISSN: 1678-765X. 
LÉVY, P. Les technologies de l’intelligence: l'avenir de la pensee a l'ere informatique. Paris: La Découverte, 1990.

LÉVY, P. L’idéographie dinamique: vers une imagination artificielle?. Paris: La Découverte, 1991.

LÉVY, P. De la programmation considerée comme un des beaux-arts. Paris: La Découverte, 1992.

LÉVY, P. L’intelligence collective. Pour une anthropologie du cyberespace. Paris: La Découverte, 1995.

LÉVY, P. O que é o virtual?. Rio de Janeiro: Editora 34, 1996.

LOJKINE, J. A revolução informacional. São Paulo: Cortez, 1995.

LYYTINEN, K. Different perspectives on information systems: problems and solutions. ACM Computing Surveys, New York, v.19, n.1, p.5-46, 1987.

MCCULLOCH, W.Embodiments of mind. Cambridge: MIT Press, 1988.

MCCULLOCH, W., PITTS, W. A Logical Calculus of the ideas Immanent in Nervous Activity. Bull. Math. Biophysics. [s.l.], n. 5, p. 115-133, 1943.

MATTELART, A. Comunicação-mundo: histórias das idéias e das estratégias. Petrópolis: Vozes, 1994.

MATURANA, H., VARELA, F. De máquinas e seres vivos. Autopoiese, a Organização do Vivo. Porto Alegre: Artes Médicas, 1997.

NEEDLEMAN, J. The heart of philosophy. Londres: Routledge, 1983.

RIBEIRO, D. Apresentação. In: BONSIEPE, G.. “Tecnologia” da tecnologia. São Paulo: Edgard Blücher, 1983. 
RUYER, R. A cibernética e a origem da informação. Rio de Janeiro: Paz e Terra, 1972.

SERIS, J.P. La technique. Paris: PUF, 1994.

SCHUMACHER, E. F. Small is beautiful: Economics as if people mattered. New York: Harper and Row, 1973.

VARELA, F.; THOMPSON, E.; ROSCH, E. L'inscription corporelle de l'esprit. sciences cognitives et expérience humaine. Paris: Seuil, 1993.

WEIZENBAUM, J. Computer power and human reason: from judgment to calculation.. San Francisco: Freeman, 1976.

WINNER, L. Autonomous technology. Technics-out-of-control as a theme in political thought. Cambridge: MIT Press, 1977.

ROSEMBlueth A., BIGELOW J. Behavior, Purpose and Teleology. Philosophy of Science, 10 (1943): 18-24.

Wittgenstein, L. (1922) Tratado Lógico-Filosófico. Investigações Filosóficas. Lisboa: Fundação Calouste Gulbenkian,1995. 


\section{Murilo Cardoso de Castro}

Graduação em Administração pela Universidade Federal do Rio de Janeiro , mestrado em Geografia pela Universidade Federal do Rio de Janeiro, doutorado em Geografia pela Universidade Federal do Rio de Janeiro e doutorado em Doutorado Sanduíche pela Universite de Paris III (Sorbonne-Nouvelle) . murilodecastro@terra.com.br

\section{Raquel Cardoso de Castro}

Graduação em Letras pela PPUC-Rio, mestrado em Ciência da Informação pelo IBICT/MCT e doutorado em Comunicação pela UFRJ. raquelcdecastro@gmail.com

João Cardoso de Castro

Graduação em Filosofia pela UERJ e mestrado em Tecnologia

Educacional para a Saúde.

Recebido em: 15/10/2007

Aceito para publicação em: jul/2008 